\title{
Tectônica transcorrente mesozoica/cenozoica na porção leste do Planalto do Rio Grande do Sul, Brasil
}

\author{
Alexis Rosa NUMMER ${ }^{1,2}$, Rômulo MACHADO³ \& Patrícia Duringer JACQUES ${ }^{2,4}$ \\ 1. Departamento de Geociências, Instituto de Agronomia, Universidade Federal Rural do Rio de Janeiro. BR 465, Km 7, CEP 23.890-000, \\ Seropédica, RJ, Brasil. E-mail: nummer@ufrrj.br. \\ 2. Programa de Pós-graduação em Recursos Minerais e Hidrogeologia, Instituto de Geociências, Universidade de São Paulo. Rua do Lago \\ 562, CEP 05508-080, São Paulo, SP, Brasil. \\ 3. Departamento de Geologia Sedimentar e Ambiental, Instituto de Geociências, Universidade de São Paulo. Rua do Lago 562, CEP 05508- \\ 080, São Paulo, SP, Brasil. E-mail: rmachado@usp.br. \\ 4. CPRM, Serviço Geológico do Brasil. Av. Pasteur, 404, Urca, Rio de Janeiro, RJ, Brasil. E-mail: patricia.jacques@cprm.gov.br.
}

Recebido em 08/2012. Aceito para publicação em 07/2014.

Versão online publicada em 19/09/2014 (www.pesquisasemgeociencias.ufrgs.br)

\begin{abstract}
Resumo - A análise estrutural de falhas e fraturas realizada em pedreiras de rochas vulcânicas da Formação Serra Geral, Bacia do Paraná, região serrana do Estado do Rio Grande do Sul, permitiu definir quatro famílias principais de falhas: NE-SW a NNE-SSW, WNW-ESE a E-W, N-S e NW-SE (menos expressivas na escala de afloramento). Os lineamentos (392) extraídos de imagens LANDSAT TM7 e do modelo digital de elevação-SRTM, na escala 1:250.000 apresentam uma frequência de estruturas com orientação dominante WNW-ESE (N60-80W), com valores menos expressivos orientados NE-SW (N30- 40E) e NNE-SSW, N0-10E). As falhas NE-SW e E-W acham-se preenchidas por microfibras de carbonatos e óxidos (de ferro e manganês) e mostram o predomínio de cinemática transcorrente destral. Já as falhas N-S e WNW-ESE não são preenchidas por microfibras, e a cinemática das transcorrências é dominantemente sinistral. A relação cronológica entre as famílias de falhas sugere três grupos de falhas transcorrentes: um mais antigo (Eocretáceo), com direção NW e cinemática destral, um intermediário (Neocretáceo ao Paleógeno), com direções N-S a NNE-SSW (destral) e ENE-SSW a E-W (sinistral), e outro mais novo (Paleógeno ao Neógeno), com direções NE-SW (destral) e NW-SE (sinistral).
\end{abstract}

Palavras-Chave: Lineamentos estruturais, análise estrutural, falhas transcorrentes, Formação Serra Geral, Bacia do Paraná.

\begin{abstract}
Cenozoic/Mesozoic transcurRent tectonics in the EASTERn Portion of Rio Grande do Sul Plateau, BRAzIL. Structural analysis of faults and fractures were carried in quarries volcanic rocks of the Serra Geral Formation, Paraná Basin, Rio Grande do Sul Plateau. They allowed defining four main families of faults: NE-SW to NNE-SSW, WNW-ESE to E-W, N-S and NW-SE. The tectonic lineaments (392) extracted from Landsat TM7 images and SRTM - digital elevation model, in the 1:250,000 scale, frequently show structures with a preferred WNW- ESE (N60 -80W) trend, and secondarily NE-SW (N30-40E) and NNE-SSW (N0 $\left.{ }^{\circ}-10 \mathrm{E}\right)$ trends. The outcrops analysis predominantly showed NE-SW and ENE to E-W trends with dextral strike-slip kinematics, and the presence of microfiber carbonates and iron manganese oxides along fault planes. On the other hand, for the patterns N-S and WNW-ESE, both dextral and sinistral strike-slip kinematics were obtained, without the filling of microfiber. A chronological relation of the different fault families establishes that the NW one is older, probably of Early Cretaceous age, and that the NE-SW and NW-SE ones with dextral and sinistral kinematics, respectively, are younger, with age between Paleogene and Neogene. However, both N-S to NNE (dextral) and ENE-WSW to E-W (sinistral) fault patterns have intermediate age, between Upper Cretaceous and Paleogene. Keywords: Structural lineaments, structural analysis, strike-slip faults, Serra Geral Formation, Paraná Basin.
\end{abstract}

\section{Introdução}

A Bacia do Paraná manifestou, ao longo de sua história, influência das estruturas do embasamento sobre o qual se estabeleceu (Almeida, 1980). Tais estruturas correspondem a linhas de fraqueza preexistentes no embasamento, constituindo os elementos mais importantes em sua evolução, reativados durante as fases tectônicas posteriores e controlando as falhas subsequentes (Fúlfaro et al., 1982). Estes autores consideram a existência de calhas aulacogênicas, alinhadas na direção NW-SE, responsáveis pela implantação da bacia, enquanto outros postulam a presença de depressões alongadas na direção NE-SW (Milani \& Ramos, 1998; Milani et al., 2007). A divergência de modelos tectônicos sobre a sua origem mostra a necessidade do uso de métodos e ferramentas com abordagens integradas para a elucidação destas questões.

A caracterização dos padrões estruturais NE e NW é um aspecto importante para delinear o controle na evolução tectono-sedimentar da bacia e da tectônica deformadora das suas unidades estratigráficas. Sabe-se, por exemplo, que o padrão estrutural NE reflete a herança tectônica das estruturas do embasamento ex- 
posto nas regiões sul e sudeste do Brasil (Fig. 1). Tais estruturas, juntamente com os padrões N-S e, subsidiariamente, E-W, acham-se evidenciados nos mapas de isópacas das unidades estratigráficas (Northfleet et al., 1969) e nas seções paleoestruturais SW-NE da bacia (Zalán et al., 1991), apresentando mudanças acentuadas nas orientações dos depocentros, como reflexo da reativação recorrente do padrão estrutural NE no decorrer de sua história.

A influência do padrão estrutural N-S manifestou-se durante a deposição da Formação Furnas, passando para o padrão NW e NNW na época de deposição da Formação Ponta Grossa, quando a bacia é então dividida em duas sub-bacias, persistindo ainda este padrão durante a deposição do Grupo Itararé e da Formação Aquidauana, apesar da notável inversão ocorrida ao longo da Zona de Falha Curitiba - Maringá (Zalán et al., 1991). Por outro lado, a Formação Rio Bonito apresenta forte controle do padrão NE, sendo, no entanto, notável a influência da Zona de Falha Lancinha-Cubatão no padrão das isópacas. No mapa de isópacas acumuladas, as formações Irati, Serra Alta, Teresina e Rio do Rasto mostram influência do padrão NNE, que é mais evidente nos mapas das formações analisadas separadamente (ver Northfleet et al., 1969).

0 Arco de Ponta Grossa, embora considerado por alguns autores (p.ex., Northfleet et al., 1969; Almeida, 1980; Fúlfaro et al., 1982) a ocorrência de atividade tectônica já no Neopaleozoico (durante o Permocarbonífero), os mapas de isópacas dos Grupo Rosário do Sul e das formações Piramboia e Botucatu demonstram que, somente no Mesozoico as suas linhas de isópacas se amoldam ao atual contorno do arco, sugerindo ser esta a sua idade (Zalán et al., 1990, 1991).

Este trabalho, além de apresentar os resultados da análise integrada de diferentes sensores remotos (imagens de satélite do sistema óptico e produtos SRTM) do leste do Planalto do Rio Grande do Sul, apresenta também uma análise geométrica e cinemática de estruturas rúpteis (juntas, falhas e estrias) das pedreiras da região, com o objetivo de avaliar em diferentes escalas as relações espaciais dos padrões estruturais que afetaram as rochas vulcânicas da Formação Serra Geral.

\section{2 Área, materiais e métodos}

\section{1 Área de estudo}

A área de estudo localiza-se na porção serrana do Estado do Rio Grande do Sul (Fig. 1), inserida integralmente no contexto das rochas vulcânicas da Formação Serra Geral. As imagens de sensoriamento remoto analisadas acham-se limitadas pelas coordenadas geográficas $-52^{\circ} 00^{\prime} /-50^{\circ} 00^{\prime}$ e $28^{\circ} 00^{\prime} /-29^{\circ} 00^{\prime}$. Os trabalhos de campo foram realizados em nove afloramentos de pedreiras de rochas vulcânicas e um em corte de estrada.

Na região serrana do Estado do Rio Grande do Sul, as litologias estudadas são constituídas por rochas vulcânicas ácidas e básicas da Formação Serra Geral (fácies Caxias do Sul, Várzea do Cedro, Esmeralda, Gramado e Paranapanema, de acordo com a classificação de Wildner, 2004).

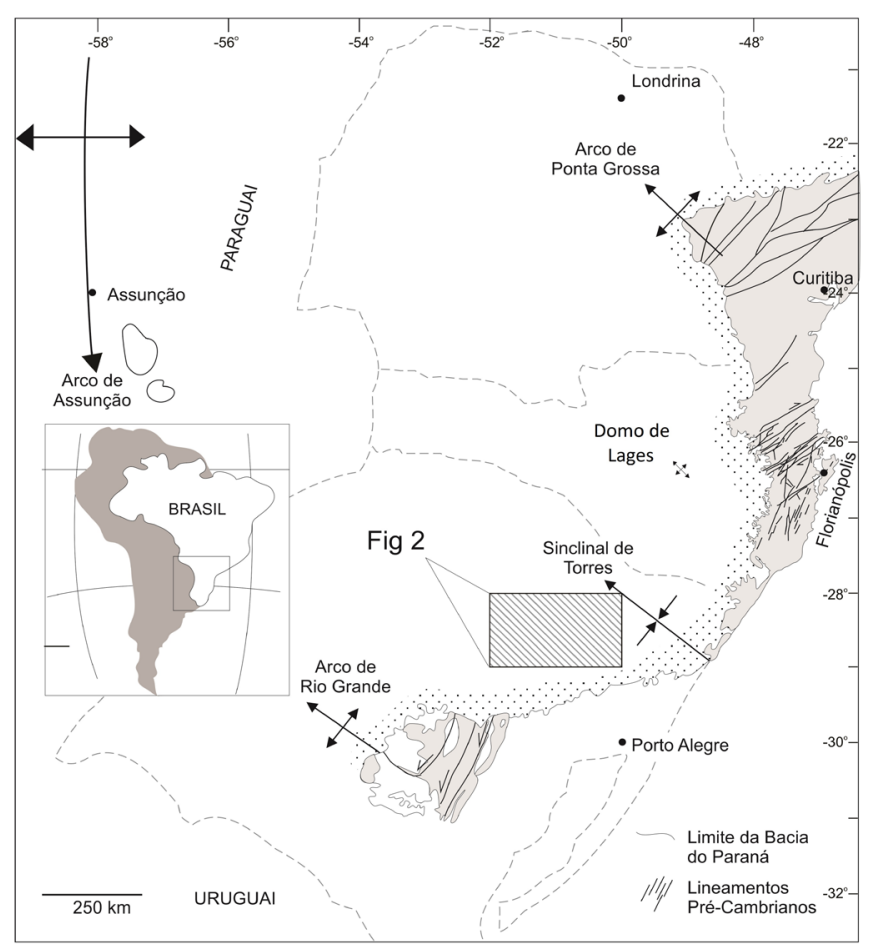

Figura 1. Localização da área de estudos (hachurada) no contexto do Estado do Rio Grande do Sul e Brasil. Em destaque os escudos Sul-rio-grandense e Catarinense com seus principais lineamentos estruturais e o limite da Bacia do Paraná nas regiões Sul e Sudeste do Brasil.

\subsection{Contexto tectônico regional}

\subsubsection{Escudo Sul-rio-grandense}

Coube a Picada $(1968,1971)$, a partir de estudos geológicos sistemáticos pioneiros realizados na região central do Escudo Sul-rio-grandense, a regionalização dos sistemas de falhas do Escudo em quatro direções principais de lineamentos: N40E (Lineamento Vigia-Roque, denominado posteriormente Sistema de Falhas Dorsal de Canguçu), N-S (Lineamento Passo do Marinheiro), N30E (Lineamento Açotéia-Piquiri) e sistema N70W (Sistema de Falhas Noroeste) (Picada, 1968). 0 primeiro sistema foi considerado mais antigo (Arqueano a Paleoproterozoico), seguido pelos sistemas N-S (Neoproterozoico), N70W (Neoproterozoico a Eopaleozoico) e N30E (Eopaleozoico). Grande parte das falhas do sistema N70W é relacionada temporalmente ao sistema N-S que, por sua vez, desloca o sistema N40E, considerado mais antigo. Os dois primeiros sistemas são de falhas de rejeito direcional e o terceiro é relacionado a uma estrutura do tipo graben (rift-valley) contendo rochas sedimentares eopaleozoicas, que foi reativado posteriormente. As últimas reativações afetam sedimentos permocarboníferos (Falha do Leão) e, provavelmente, do Quaternário - Pleistoceno (Picada, 1968). 
As falhas mais proeminentes do escudo fazem parte do Sistema de Falhas Dorsal de Canguçu, ao longo do qual se alinham rochas metamórficas do Grupo Porongos, corpos de granitos (p. ex., Granito Cordilheira) e migmatitos (Formação Vigia-Roque) recortados por brechas, milonitos e cataclasitos (Picada, 1971).

Investigações tectônicas no Escudo, com o uso de imagens de satélite e radar, realizadas por Ribeiro (1980), evidenciaram os lineamentos N50E como a direção mais saliente, seguida pelos de direção N50W, N25-30E, N80W e N10-15E. Os dois primeiros, considerados contemporâneos por Ribeiro (1970), atravessam todo o escudo e são afetados pelos dois últimos, com provável idade mesozoica. Os lineamentos N50E e N50W, denominados de geossuturas por Ribeiro (1980), são alinhados, com espaçamento regular (5 a $20 \mathrm{~km}$ ) e extensão de 200 a $300 \mathrm{~km}$.

Estudos sobre a tectônica deformadora da Bacia do Camaquã definiram quatro grupos de falhas com idades e campos de esforços distintos, sendo três deles transcorrentes e um normal (Almeida, 2005). Os dois primeiros grupos de transcorrências são associados com a geração simultânea de duas direções de falhas (próximas de E-W e de N-S) com cinemática sinistral e duas direções (próximas de N-S e de E-W) com cinemática destral e um grupo de transcorrência (direção $\sim$ de ESE) com estrias horizontais, porém com cinemática não definida. O quarto grupo de falhas (normal) possui direção próxima de ESE. 0 primeiro grupo de falhas transcorrentes (E-W sinistral e N-S destral) foi relacionado a um evento compressivo NE, de idade $\sim 545 \mathrm{Ma}$, o segundo grupo de transcorrências (N-S sinistral e E-W destral), a um evento compressivo NW, com idade $\sim 530 \mathrm{Ma}$ (idades Ar-Ar), e o terceiro grupo de falhas foi relacionado a um novo evento compressivo NE, de idade triássica, que afeta somente as unidades inferiores do Grupo Rosário do Sul. 0 quarto grupo de falhas (normais) foi relacionado a um campo de esforços distensivos de idade pós-triássica, com orientação próxima de NNE, evento possivelmente responsável pelos diques alimentadores do vulcanismo da Formação Serra Geral e soerguimento do Alto Estrutural do Rio Grande (Almeida, 2005).

Almeida et al. (2010) relacionam as falhas da Bacia do Camaquã com direções de anisotropia do seu embasamento e destacam as direções NNE e NE, que estão presentes nas rochas que compõem o Cinturão Dom Feliciano e as porções norte e leste do Terreno Vacacaí.

\subsubsection{Bacia do Paraná: arcabouço estrutural}

Para Almeida (1983), os arqueamentos e flexuras da Bacia do Paraná parecem estar ligados à própria evolução da bacia e teriam sido realçados no Mesozoico, quando foram afetados inicialmente pelo magmatismo basáltico e alcalino e novamente pelo magmatismo alcalino. Durante o vulcanismo da Formação Serra Geral houve uma reorganização geral da bacia, havendo uma tendência de avanço das unidades vulcânicas sobre o Arco de Ponta Grossa, momento em que as estruturas NW voltaram a ter grande influência na sua evolução (Zalán et al., 1991).

Zalán et al. (1990) salientam as diferenças entre os padrões estruturais das zonas de falhas NW e NE. As primeiras, ao contrário das últimas, foram fortemente reativadas durante a ruptura juro-cretácica do Gondwana, e acham-se geralmente preenchidas por diques de diabásio. Caracterizam-se por extensas zonas retilíneas de falhas, que podem se alargar ou se estreitar ao longo do seu traçado, a exemplo da zona de falha Curitiba-Maringá, inserindo inteiramente o eixo do Arco de Ponta Grossa, que é limitada ao norte pela falha de São Jerônimo- Curiúva e ao sul pela falha do Rio Alonso,

O padrão NE é constituído em geral por uma única falha larga ou por uma zona de falha retilínea, sendo muito mais comuns movimentações transcorrentes do que no padrão NW, embora aqui tais movimentações também sejam frequentes (Zalán et al., 1990).

As informações geofísicas (aeromagnéticas) confirmam a existência dos alinhamentos estruturais NW-SE (Guapiara, São Jerônimo - Curiúva, Rio Alonso e Rio Piquiri), que atravessam os terrenos pré-cambrianos e penetram na bacia até a altura do Rio Paraná, por uma extensão não inferior a $600 \mathrm{~km}$, e largura entre $20 \mathrm{a}$ $100 \mathrm{~km}$ (Ferreira, 1982). Segundo o autor, tais alinhamentos apresentam atividade tectônica desde o Devoniano, com máxima atividade durante a Reativação Wealdeniana, no Juro-Cretáceo.

Estudos de lineamentos estruturais da Bacia do Paraná com uso e análise de imagens de satélite e de radar, em escala 1: 250.000, realizados por IPT (1982), evidenciaram seis direções estruturais principais nas áreas da Formação Serra Geral e seis nas coberturas sedimentares, que apresentam grande dispersão das direções.

Paiva Filho et al. (1982) aplicam metodologia semelhante no estudo da Formação Serra Geral no Sul do Brasil (Paraná, Santa Catarina e Rio Grande do Sul) e evidenciaram arqueamentos regionais (negativos e positivos) com eixos WNW. As estruturas teriam sido alçadas como resultado de esforços, a exemplo das antéclises (arcos) de Ponta Grossa e do Rio Grande.

Estudos estruturais e de fotos aéreas na escala 1:60.000, realizados na região nordeste do Rio Grande do Sul, na Bacia Hidrográfica Taquari-Antas, voltados para a caracterização de aquíferos fraturados na Formação Geral, definiram quatro direções de lineamentos: N20-30E, N40-50E, N70-80E e N30-60W, sendo esta última a direção principal (Reginato \& Strieder, 2006). As três primeiras direções são as que possuem maior associação com os aquíferos fraturados. Além disso, os autores definiram dois campos de tensões principais: um mais antigo, orientado E-W e outro mais novo, orientado N-S. Freitas (2005) e Freitas \& Rostirolla (2005), ao estudarem lineamentos regionais no sul do Paraná e norte de Santa Catarina com o uso de técnicas integradas (sensores remotos, geologia de campo, métodos potenciais, gravimétricos e magnéticos), distinguem cinco direções principais: N60-70E, 

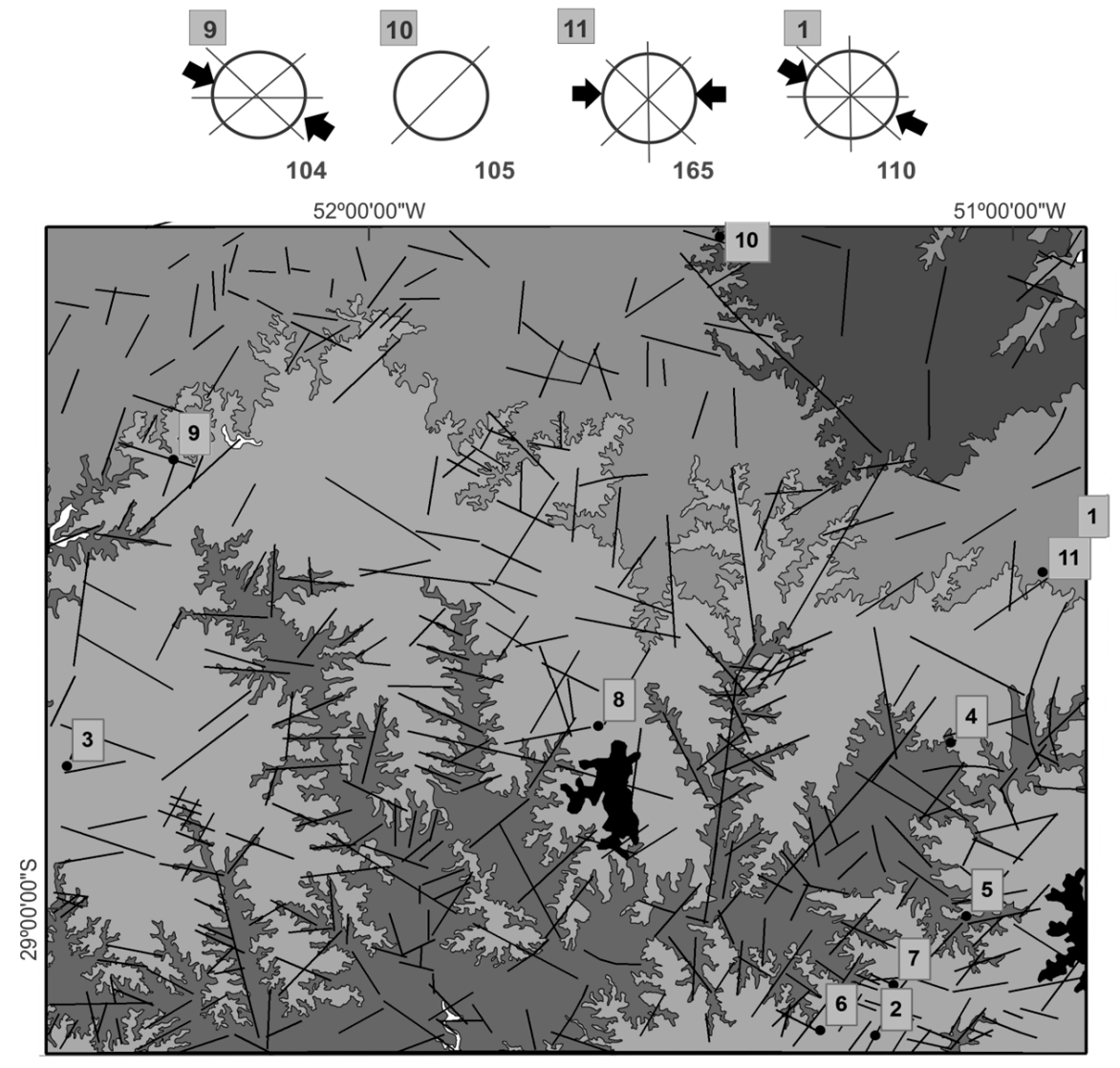

110

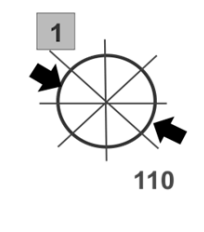

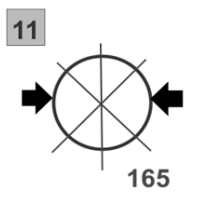

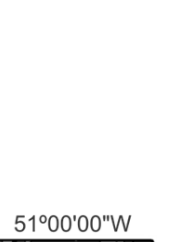

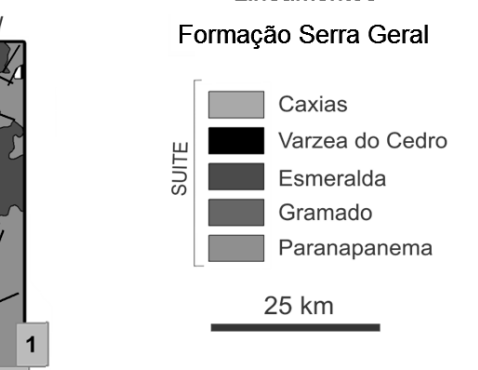

\section{A}

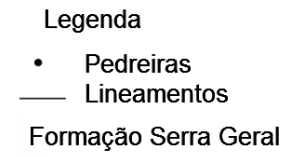

A
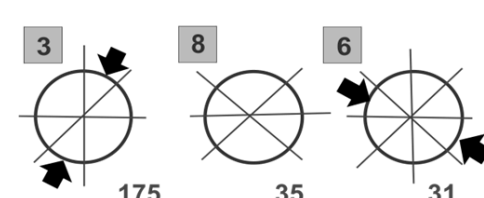

31

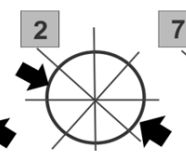

108

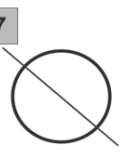

30

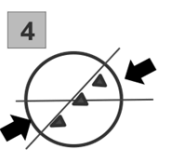

64

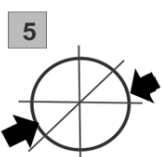

110

Figura 2. Síntese da geologia com localização das pedreiras analisadas: A) Principais lineamentos extraídos de imagens SRTM-3 da Formação Serra Geral no Leste do Planalto do Rio Grande do Sul; B) Diagramas de roseta dos lineamentos interpretados a partir de imagens de satélite LANDSAT TM7 e do Projeto SRTM, na escala 1: 250.000, incluindo diagrama total de lineamentos (Bc), e os diagramas de roseta dos lineamentos $(\mathrm{Ba}, \mathrm{Bb})$, com destaque das orientações WSW, NE-SW e NNE (Ba, Bb).

N30-40E, NNE a NNW, NW e E-W. Além disso, definem dois eventos deformacionais rúpteis: um evento mais antigo (D1), do Eocretáceo, com campo de tensões principal NNW-SSE, e um evento mais novo (D2), do Neocretáceo ao Terciário, com campo de tensões principal ENE-WSW.

Soares et al. (2007) comparam os diferentes mapas regionais (SRTM, LANDSAT, mapas magnéticos e gravimétricos) disponíveis sobre o Aquífero Guarani com o modelo digital de terreno e concluem que as direções NW $(N 45 \pm 15 W)$ e NE $(N 45 \pm 15 E)$ são aquelas que possuem altos índices de concordância, enquanto as direções NNE, NNW, N-S e E-W revelam muito baixos índices de concordância.

Freitas et al. (2002), com base em estudos de imagens LANDSAT e mosaicos de radar do Projeto RADAMBRASIL, elaboram um mapa de lineamentos em escala 1: 250.000 da porção oeste de Santa Catarina e destacam como direções principais N30-50E e N40-60W e, secundariamente, $\mathrm{N}-\mathrm{S}$ e E-W.

Jacques et al. (2010), a partir da análise digital de imagens LANDSAT e SRTM, usando duas escalas de análise - 1:100.000 e 1:500.000, definem na borda leste da Bacia do Paraná e no pré-Cambriano em Santa Catarina as seguintes direções preferenciais de lineamentos: N-S $\pm 5^{\circ}$ e, secundariamente, NNE-SSW (Escudo Catarinense), NW-SE e N-S $\pm 5^{\circ}$ (Sequência Gondwânica) e NE-SW e NW-SE (Formação Serra Geral). As imagens de relevo sombreado do Modelo Digital de Elevação (MDE) do SRTM fornecem maior dispersão de direções de lineamentos do que as imagens LANDSAT. Os lineamentos na escala 1:100.000 mostram, nos três domínios analisados, intensidade e densidade mais homogêneas do que na escala 1:500.000. Na primeira escala destacam-se as estruturas crustais mais rasas e na segunda escala, as estruturas crustais mais profundas.

Estudos de lineamentos estruturais na região do Domo de Lages, incluindo análise integrada de diferentes produtos digitais (imagens de satélite, mapas diversos, de rugosidade, declividade, morfométrico, modelo digital de terreno etc.), destacam cinco direções estruturais principais: WNW, N-S, NNE, ENE e NW (Roldan, 2007; Roldan et al., 2010). As três primeiras direções apresentam maiores frequências acumuladas, e as três últimas, maiores comprimentos acumulados. Destacam-se como lineamentos mais extensos as dire- 
ções ENE (4 a $40 \mathrm{~km}$ ) e, secundariamente, NNE e NW. São descritas falhas transcorrentes destrais N-S, NNE e $\mathrm{NE}$, e sinistrais WNW e E-W, as quais afetam as rochas alcalinas do referido domo (Roldan, 2007). 0 sistema NW-SE possui traçado extremamente planar na escala de afloramento e corta sistematicamente os demais.

A estruturação do domo foi relacionada a um regime de esforços compressivos NE-SW, que teria permanecido ativo durante e após a intrusão das rochas alcalinas. Além disso, foi responsável pela geração de falhas transcorrentes destrais (NNE-SSW e NE-SW) e sinistrais (E-W), que afetam as rochas da região (Roldan, 2007).

Estudos de correlação estrutural entre dados geofísicos (alinhamentos magnetométricos) e de imagens SRTM (lineamentos), realizados na borda leste da Bacia do Paraná em Santa Catarina e no Escudo Catarinense, mostram claro prolongamento das estruturas dúcteis NE do embasamento no substrato da bacia, bem como a reativação deste padrão estrutural no Fanerozoico (Jacques et al., 2014), particularmente como falhas transcorrentes entre o Neocretáceo e o Paleógeno (Zalán et al., 1987, 1990; Ferreira \& Almeida, 1989; Almeida, 2005; Roldan, 2007; Machado et al., 2012).

\subsection{Métodos}

\subsubsection{Análise dos lineamentos por sensores remotos e ge- oprocessamento}

Os lineamentos estruturais foram extraídos e interpretados a partir da análise digital de imagens de relevo sombreado oriundos do SRTM-3 (Shuttle Radar Topography Mission) (Farr et al., 2007), com o uso de técnicas de geoprocessamento. As imagens foram obtidas a partir do sítio do GLCF (Global Land Cover Facility - http://glcf.umd.edu/data/) com resolução espacial de 3 arcos segundo ( $90 \mathrm{~m}$ ).

No presente trabalho, buscou-se ampliar a análise macroscópica de lineamentos, realizada conforme metodologia empregada em Jacques et al, (2010), com objetivo de avaliar o padrão das estruturas rúpteis que afetam as rochas vulcânicas na aba sul do Sinclinal de Torres (Fig. 1). As estruturas lineares foram obtidas sobre imagens de relevo sombreado do MDE-SRTM, na escala 1:250.000, que se mostraram mais adequadas ao estudo das estruturas rúpteis na escala regional.

As imagens foram reamostradas para $30 \mathrm{~m}$ pelo método matemático de convolução cúbica, visando melhorar visualmente as imagens de relevo sombreado sobre as quais foram extraídos manualmente os lineamentos. As imagens derivadas de relevo sombreado foram realizadas em quatro azimutes perpendiculares entre si: $000^{\circ}, 045^{\circ}, 090^{\circ}$ e $315^{\circ}$, e a inclinação solar utilizada foi $45^{\circ}$, de acordo com a indicação de Crepani \& Medeiros (1994).

As estruturas interpretadas e traçadas nas imagens referem-se às falhas, fraturas, vales (negativas) e cristas alinhadas (positivas). Cada conjunto de estrutu- ra foi avaliado isoladamente e agrupado de acordo com os sistemas preferenciais dos lineamentos.

Metodologia semelhante tem sido utilizada por vários autores em diferentes áreas no sul e sudeste do Brasil (Freitas, 2005; Roldan, 2007; Soares et al., 2007; Strugale et al., 2007, dentre outros), porém não foi ainda empregada na região do Planalto Sul-rio-grandense.

\subsubsection{Análise estrutural}

Os trabalhos de campo foram programados em áreas específicas da região serrana do Rio Grande do Sul, de forma que coincidissem com lineamentos importantes projetados a partir do embasamento do escudo. Foram realizadas duas etapas de campo, com o total de 16 dias, que propiciaram desenvolver o estudo das principais pedreiras em atividade da região e coletar sistematicamente 1019 medidas de dados estruturais pareados (plano de falha e estria correspondente).

Estes dados, depois de digitados em planilha Excel, foram separados em famílias de falhas e incorporados ao programa TectonicsFP (Reiter \& Acs, 1995), onde foram gerados os diagramas para análise geométrica e cinemática das estruturas.

Os diagramas de diedros retos (Angelier \& Mechler, 1977) permitiram estimar os diferentes campos de tensões para as famílias de falhas com cinemática definida. Estes diagramas foram determinados pelas intersecções dos diedros opostos (compressão ou esforço máximo e distensão ou esforço mínimo) pertencentes ao mesmo sistema e relacionados ao movimento específico da estria contida no plano de falha.

\section{Resultados}

\subsection{Análise dos lineamentos por sensores remotos e geo- processamento}

Foram analisados 392 lineamentos na escala $1: 250.000$, que apresentam nos diagramas de roseta um padrão estrutural predominante WNW-ESE e, secundário, NE-SW e NNE-SSW (Fig. 2A).

Os lineamentos de maior comprimento ou intensidade possuem direção preferencial WNW-ESE (entre $\mathrm{N} 60^{\circ}-70^{\circ} \mathrm{W}$ ), enquanto os lineamentos de menor extensão, porém com maior densidade, apresentam direção WNW-ESE (entre $\mathrm{N} 60^{\circ}-80^{\circ} \mathrm{W}$ ) e coincidem com os primeiros em termos de intensidade. Os padrões dos lineamentos são semelhantes na escala macroscópica, porém são diferentes em termos cinemáticos na escala de afloramento.

\subsection{Análise geométrica e cinemática das falhas}

Os dados estruturais (1019 medidas) obtidos na área estudada são apresentados por pedreira analisada (12 colunas) e pelas direções das famílias de falhas/ 
fraturas presentes em cada uma delas (linhas), cujas direções dominantes podem ser observadas nos diagramas de roseta das figuras $3 \mathrm{~A}-\mathrm{B}$. 0 quadro 1 apresenta os diagramas de roseta (B) de cada afloramento visitado. Em algumas pedreiras não foi possível determinar com segurança a cinemática de alguns padrões de falhas transcorrentes, razão pela qual se optou por indicar como 'indefinido' no referido quadro.

O material de preenchimento que compõe as microfibras no planos das diferentes famílias de falhas analisadas é composto em geral por carbonatos (calcita espática bem cristalizada ou eventualmente micrítica), sendo particularmente importante no padrão de falhas de orientação N-S.

Na pedreira da Mineração Brasil, em Passo Fundo, ocorrem microbrechas piroclásticas encaixadas em rochas vulcânicas ácidas (Suíte Caxias do Sul, segundo Wildner, 2004) associadas ao padrão de falhas WNW-ESE, sugerindo controle das mesmas por este padrão.

$\mathrm{Na}$ pedreira São Marcos, observam-se falhas transcorrentes que afetam rochas hidrotermalizadas, sugerindo reativação em época mais recente de direções estruturais anteriores.

Nas pedreiras de Lagoa Vermelha e Vacaria (Mineração Brasil), associadas às suítes vulcânicas Esmeralda e Gramado (Wildner, 2004), ocorrem microfibras de óxidos de ferro e manganês em planos de falhas com geometria sinuosa e anastomosada, que é diferente dos padrões de falhas observados nas outras pedreiras estudadas.

A análise conjunta em projeção estereográfica (Fig. 3A) dos dados estruturais das pedreiras estudadas mostra as seguintes direções de falhas: NE-SW, NNE-SW a N-S, ENE-WSW a E-W e NW-SE. As três primeiras direções são também registradas no diagrama de roseta (Fig. 3B), aparecendo ainda o padrão ESE-WNW. As falhas transcorrentes NE-SW são predominantes nas pedreiras analisadas, seguidas pelas falhas NW-SE e E-W. São falhas de alto ângulo de mergulho, com estrias em geral de baixo caimento, típicas de falhas transcorrentes (destrais e sinistrais), algumas delas reativadas como falhas normais e, mais raramente,

Quadro 1. Síntese das informações estruturais dos afloramentos estudados neste trabalho. Foram analisadas 10 pedreiras em atividade e um afloramento em corte de estrada, que se acham representadas pelas seguintes siglas: VAC - Vacaria (A), CXS - Caxias do Sul (B), SOL - Soledade (C), CAM - Campestre da Serra (D), SMA - São Marcos- Pedreira IBC (E), BGO - Bento Gonçalves - Pedreira Toniolo-Busnelo (F), FAR -Farroupilha- Pedreira Caxiense-Fagundes (G), NPR - Nova Prata - Pedreira Vila Sabiá (H), MAR - Marau - Passo Fundo - Pedreira Andreatta (I), BRA - Lagoa Vermelha - BR 470 - Mineração Brasil (J), PVA - Vacaria - Pedreira Bricon (K), cc: com cinemática definida; sc: sem cinemática definida.

\begin{tabular}{|c|c|c|c|c|c|c|c|c|c|c|c|}
\hline & VAC & CXS & SOL & CAM & SMA & BGO & FAR & NPR & MAR & BRA & PVA \\
\hline $\begin{array}{c}\text { Pedreiras } \\
\text { analisadas }\end{array}$ & (A) & (B) & (C) & (D) & (E) & (F) & (G) & (H) & (I) & (J) & (K) \\
\hline $\begin{array}{c}\text { № de } \\
\text { medidas }\end{array}$ & 165 & 110 & 175 & 110 & 64 & 31 & 108 & 35 & 104 & 105 & 30 \\
\hline \multirow{3}{*}{$\begin{array}{c}\text { Família de } \\
\text { falhas / } \\
\text { fraturas } \\
\text { dominantes }\end{array}$} & NE/SW & NE/SW & NE/SW & $\mathrm{NE} / \mathrm{SW}$ & EW & $\mathrm{NE} / \mathrm{SW}$ & NW/SE & EW & EW & $\mathrm{NE} / \mathrm{SW}$ & NW/SE \\
\hline & Riedel & Riedel & Riedel & Riedel & Riedel & Riedel & Riedel & Riedel & Riedel & & \\
\hline & $17 \mathrm{cc} / 5 \mathrm{sc}=$ & $7 \mathrm{cc} / 29 \mathrm{sc}=$ & $6 \mathrm{cc} / 3 \mathrm{sc}=$ & $7 \mathrm{cc} / 29 \mathrm{sc}=$ & & $1 \mathrm{cc}=$ & $3 \mathrm{cc} / 12 \mathrm{sc}=$ & $1 \mathrm{sc}=$ & $3 \mathrm{cc} / 18 \mathrm{sc}=$ & & \\
\hline NNE/SSW & 22 & 36 & 9 & 36 & $\begin{array}{c}\text { Não } \\
\text { observado }\end{array}$ & 1 & 15 & 1 & 21 & $\begin{array}{c}\text { Não } \\
\text { observado }\end{array}$ & $\begin{array}{c}\text { Não } \\
\text { observado }\end{array}$ \\
\hline \multirow[t]{2}{*}{ e NS } & indefinido/ & Indefinido/ & indefinido/ & indefinido/ & & destral & destral & indefinido & indefinido & & \\
\hline & sinistral & sinistral & sinistral & sinistral & & & & & & & \\
\hline \multirow[t]{4}{*}{ EW } & $1 \mathrm{cc} / 17 \mathrm{sc}=$ & $4 \mathrm{cc} / 3 \mathrm{sc}=$ & $6 \mathrm{cc} / 4 \mathrm{sc}$ & $4 \mathrm{cc} / 3 \mathrm{sc}=$ & $14 \mathrm{cc} / 22 \mathrm{sc}=$ & $4 \mathrm{cc}=$ & $5 \mathrm{cc} / 17 \mathrm{sc}=$ & $10 \mathrm{cc} / 5 \mathrm{sc}=$ & $6 \mathrm{cc} / 17 \mathrm{sc}=$ & & \\
\hline & 18 & 7 & 10 & 7 & 36 & 4 & 22 & 15 & 23 & $\begin{array}{c}\text { Não } \\
\text { observado }\end{array}$ & \\
\hline & Sem definição & indefinido/ & indefinido/ & indefinido/ & reversa/ & destral & destral & destral/ & indefinido/ & & $\begin{array}{c}\text { Não } \\
\text { observado }\end{array}$ \\
\hline & & sinistral & destral & sinistral & sinistral & & & indefinido & destral & & \\
\hline \multirow[t]{4}{*}{ NE/SW } & $18 \mathrm{cc} / 63 \mathrm{sc}=$ & $13 \mathrm{cc} / 40 \mathrm{sc}=53$ & $35 \mathrm{cc} / 81 \mathrm{sc}=$ & $13 \mathrm{cc} / 40 \mathrm{sc}=$ & $26 \mathrm{cc} / 2 \mathrm{sc}=$ & $4 \mathrm{cc} / 16 \mathrm{sc}=$ & $7 \mathrm{cc} / 13 \mathrm{sc}=$ & $5 \mathrm{cc} / 8 \mathrm{sc}=$ & $7 \mathrm{cc} / 32 \mathrm{sc}=$ & $29 \mathrm{cc} / 76 \mathrm{sc}=$ & \\
\hline & 81 & destral/ & 116 & 53 & 28 & 20 & 20 & 13 & 39 & 105 & $\begin{array}{c}\text { Não } \\
\text { observado }\end{array}$ \\
\hline & indefinido/ & indefinido & destral/ & indefinido/ & $\begin{array}{c}\text { ind } / \text { sinistral/ } \\
\text { reversa }\end{array}$ & destral/ & destral/ & destral & destral & destral & \\
\hline & destral & & indefinido & destral & & indefinido & normal & & & & \\
\hline \multirow[t]{4}{*}{ NW/SE } & $4 \mathrm{cc} / 40 \mathrm{sc}=$ & $14 \mathrm{sc}=$ & $1 \mathrm{cc} / 39 \mathrm{sc}=$ & $14 \mathrm{sc}=$ & & $2 \mathrm{cc} / 4 \mathrm{sc}=$ & $7 \mathrm{cc} / 44 \mathrm{sc}=$ & $4 \mathrm{cc} / 2 \mathrm{sc}=$ & $6 c c / 15 s c=$ & & $2 \mathrm{cc} / 28 \mathrm{sc}=$ \\
\hline & 44 & 14 & 40 & 14 & $\begin{array}{c}\text { Não } \\
\text { observado }\end{array}$ & 6 & 51 & 6 & 21 & $\begin{array}{c}\text { Não } \\
\text { observado }\end{array}$ & 30 \\
\hline & Pred. sinistral & indefinido & indefinido & indefinido & & Destral/ & Sinistral/ & destral & normal/ & & sinistral \\
\hline & & & & & & sinistral & destral & & sinistral & & \\
\hline
\end{tabular}




(t)

Figura 3. Principais famílias de falhas analisadas na região serrana do estado do Rio Grande do Sul: A) Diagramas tipo Beta com a simbologias correspondentes aos tipos de movimentos ocorridos ao longo dos planos de falha, a saber: 7 (transcorrente destral a levemente oblíqua); ${ }^{-}$(transcorrente sinistral a levemente oblíqua); - - (transcorrente pura), $\Theta$ (normal), $\Theta$ (inversa); B) Diagramas de rosetas (circulo maior) com pétalas distribuídas em intervalos de $10^{\circ}$, mostrando a orientação preferencial das medidas (esquerda das figuras); Diagramas representativos da máxima declividade com intervalos de $15^{\circ}$ (direita das figuras); C) Posicionamento dos campos de tensão máxima $\circ\left(\sigma_{1}\right)$, intermediária $\square\left(\sigma_{2}\right)$ e mínima $\Delta\left(\sigma_{3}\right)$; D) Diagrama dos Diedros Retos com a posição dos campos de compressão (cinza) e extensão (em branco) máximos.

como falhas oblíquas. As falhas transcorrentes ocorrem segundo as quatro direções acima, e apenas o padrão NE-SW apresentou consistência cinemática nas pedreiras analisadas, enquanto os demais padrões de falhas (NNE-SSW a N-S, ENE-SSW a E-W e NW-SE) apresentam movimentações destral e sinistral, sugerindo que estas estruturas foram sujeitas a pelo menos dois campos de tensões (Fig. 3C-D) com direções distintas, conforme será discutido mais adiante.

As direções dos lineamentos extraídos das imagens na escala 1:250.000 (NE-SW, NNE e WNW-ESE) (Fig. 2A) acham-se também representados nos diagramas de projeção estereográfica do conjunto das pedreiras analisadas (Fig. 3A) e são compatíveis com os padrões de falhas transcorrentes caracterizados na escala de afloramento. Os lineamentos ESE-WNW aparecem como padrão principal na escala da imagem, exibindo maior comprimento e intensidade, seguidos pelos lineamentos NE-SW, que aparecem como padrão principal na escala de afloramento e correspondem a falhas de natureza transcorrente, algumas delas reativadas como falhas normais.

\section{Discussão}

O padrão de falha transcorrente destral NE-SW, caracterizado em todas as pedreiras estudadas, juntamente com o padrão transcorrente sinistral NW-SE, identificado em várias pedreiras (VAC, BGO, FAR e MAR), pode ser explicado segundo um mesmo campo de esforços com eixo de tensão máxima $\left(\sigma_{1}\right)$ ao redor de E-W (Quadro 1). 0 primeiro padrão de transcorrência NE-SW (destral) possui a mesma orientação estrutural do Escudo Catarinense (Fig. 1) e do substrato da Bacia do Paraná em Santa Catarina (Jacques et al., 2014), sugerindo tratar-se da reativação de estruturas pré-cambrianas no Fanerozoico, particularmente entre o Neocretáceo e o Paleógeno, conforme tem sido postulado por vários autores (Zalán et al., 1987, 1990; Ferreira \& Almeida 1989; Almeida, 2005; Roldan et al., 2010, dentre outros).

O campo de tensão ao redor de E-W aqui sugerido é compatível com o do evento deformacional $\mathrm{D}_{2}$, com idade entre o Eocretáceo e o Paleógeno, definido na região do Arco de Ponta Grossa (Strugale, 2002; Strugale et al., 2007). Para os autores, este evento ocorreu em regime transtrativo e gerou bandas de deformação em arenitos e reativou paredes de diques básicos NW-SE 
associados ao referido arco.

As falhas transcorrentes destrais NW-SE, descritas nas pedreiras BGO, FAR e NPR, podem ser explicadas por um campo de esforços com eixo de tensão máxima $\left(\sigma_{1}\right)$ próximo de N-S, idêntico ao proposto por Reginato \& Strieder (2006) na região da Bacia Hidrográfica Taquari-Antas, em rochas da Formação Serra Geral, porém, a idade deste padrão seria mais antiga do que ao padrão E-W, ao contrário do que foi proposta pelos autores acima. Campo de tensões com orientação similar- do Eocretáceo - foi definido por Strugale (2002) e Strugale et al. (2007) para as transcorrências NW-SE associadas ao Arco de Ponta Grossa. Os autores relacionam este campo de tensões a um regime distensivo que controlou a intrusão de enxame de diques NW-SE do arco

$\mathrm{O}$ padrão de falha transcorrente destral $\mathrm{N}-\mathrm{S}$, observado nas pedreiras SMA, BGO, FAR e BRA (Quadro 1), é compatível com um campo de tensões NE-SW. Este mesmo campo de tensões poderia explicar também o padrão de transcorrência sinistral ao redor de E-W, descrito em duas pedreiras estudadas (CAM e SMA). 0 campo de tensões acima é similar ao que foi definido no Domo de Lages, SC, onde são descritos os mesmos padrões de falhas transcorrentes (Roldan, 2007; Roldan et al., 2010; Machado et al., 2012). Tais falhas cortam rochas alcalinas associadas ao domo, cuja idade $(\mathrm{Rb} / \mathrm{Sr}$, $\mathrm{K} / \mathrm{Ar}, \mathrm{Ar} / \mathrm{Ar}$ ) situa-se ao redor de $75 \mathrm{Ma}$ (Scheibe et al., 1985; Machado \& Teixeira, 2008), sugerindo o desenvolvimento destas estruturas entre o Neocretáceo e o Paleógeno (Roldan, 2007; Machado et al., 2012).

Este mesmo campo de tensões é compatível com o das transcorrências sinistrais E-W de idade paleocênica/eocênica ou neogênica (Mioceno), que afetaram o Maciço Alcalino de Cananéia e foram responsáveis pelo controle e instalação de pequenas bacias sedimentares, como a de Itaquaquecetuba (Formação Itaquacetuba), bem como pela formação de dobras cônicas na Bacia de Taubaté (Riccomini, 1989, 1995; Riccomini et al., 2005). De acordo com os mesmos autores, este evento seria anterior ao evento de distensão crustal com direção NNW-SSE, responsável pela instalação das bacias tafrogênicas do Rifte Continental do Sudeste do Brasil, com idade do Paleógeno (Eoceno-Oligoceno).

As transcorrências NE e NNE sugerem influência direta das orientações das foliações metamórficas e/ou cataclásticas de idades reconhecidamente pré-cambrianas, que têm sido observadas amplamente no Escudo Sul-rio-grandense, particularmente no Cinturão Dom Feliciano, assim como as falhas de direção WNW, reportadas por outros autores e que fazem parte do Sistema de Falhas Noroeste, definido originalmente por Picada (1968). A existência de falhas que afetam o solo na pedreira da Mineração Brasil (BRA) sugere atividade tectônica extremamente recente na região ou até mesmo atual.

\section{Conclusões}

0 padrão geométrico e cinemático de falhas transcorrentes caracterizadas neste trabalho (NE-SW, NNE-SSW, NW-SE, ENE-WSW a E-W) é semelhante ao padrão estrutural descrito por outros autores na borda leste da Bacia do Paraná - regiões do Arco de Ponta Grossa (PR) e do Domo de Lages (SC), ressaltando-se aqui o predomínio das transcorrências NE-SW em todas as pedreiras analisadas, e o de lineamentos WNW-ESE nas imagens de radar.

O sistema de falhas transcorrentes NE-SW (destral) e NW-SE (sinistral) que afeta as rochas vulcânicas da Formação Serra Geral no leste do Planalto do Rio Grande Sul pode ser explicado em um mesmo campo de esforços com tensão máxima $\left(\sigma_{1}\right)$ ao redor de E-W. $O$ padrão transcorrente destral NE-SW parece reativar estruturas já existentes no embasamento da Bacia do Paraná e no Escudo Catarinense (ver Fig. 1), enquanto o padrão transcorrente NW-SE (sinistral) corresponde aparentemente uma direção estrutural mais nova na bacia que foi nucleado no Cretáceo como reflexo da ruptura continental do Gondwana ligada à abertura do Oceano Atlântico Sul.

Já o padrão transcorrente NW-SE, destral, parece ser mais antigo do que o padrão transcorrente sinistral de mesma orientação. Trata-se de um padrão estrutural que foi implantado de forma independente da orientação das estruturas do embasamento da bacia. Este padrão transcorrente pode ser explicado com base em um campo de esforços compressivos orientado próximo de N-S, a exemplo do que tem sido descrito em estruturas similares no Paraná (Domo de Guatiguá e Arco de Ponta Grossa). Ressalte-se ainda que a orientação estrutural NW-SE está presente em estruturas regionais (arcos e flexuras) desenvolvidas na borda leste e sul da Bacia do Paraná, entre os estados do Paraná e Rio Grande do Sul.

O campo de tensões NE-SW definido neste trabalho parece ser mais recente do que o campo de tensões $\mathrm{N}-\mathrm{S}$. A julgar pelos trabalhos disponíveis em outras regiões da bacia nos estados do Paraná (Arco de Ponta Grossa e Domo de Guatiguá) e Santa Catarina (Domo de Lages), o primeiro campo de tensões pode ser relacionado a um evento de deformação com idade situada entre o fim do Cretáceo e início do Paleógeno, uma vez que no Domo de Lages ele afeta as rochas alcalinas com idade ao redor de $75 \mathrm{Ma}$. Já o segundo campo de tensões N-S deve ser mais antigo, podendo ser relacionado a um evento de deformação com idade eocretácea.

Em síntese, as estruturas transcorrentes discutidas neste trabalho podem ser agrupadas em três eventos deformacionais: um mais antigo $\left(D_{1}\right)$, com tensão máxima principal $(\sigma 1)$ orientada o redor de N-S, um intermediário $\left(\mathrm{D}_{2}\right)$, com tensão máxima principal $(\sigma 1)$ disposta aproximadamente NE-SW, e outro mais novo $\left(D_{3}\right)$, onde a tensão máxima $(\sigma 1)$ orienta-se ao redor de E-W. Estas fases de deformação foram provavelmente 
ativas, respectivamente, no Eocretáceo, do Neocretáceo ao Paleógeno, e do Paleógeno ao Neógeno. A fase $\mathrm{D}_{1}$ foi responsável pela geração de uma direção estrutural não encontrada em geral no embasamento exposto da bacia. Já a fase $\mathrm{D}_{2}$, ao contrário, reativou estruturas preexistentes nos escudos Catarinense e Sul-Rio-Grandense ( $N E$ e NNE), e a fase $D_{3}$ também reativou o padrão estrutural NE do Escudo Catarinense e as estruturas NW geradas na primeira fase de deformação.

0 quadro cinemático aqui apresentado mostra uma rotação no sentido horário ao redor de $90^{\circ}$ dos eixos de tensão máxima da primeira fase de deformação $\left(D_{1}\right)$ para os eixos da terceira fase $\left(D_{3}\right)$, com esta rotação sendo no mesmo sentido de migração da placa Sul-Americana após o evento de abertura do Oceano Atlântico Sul.

Agradecimentos- Os autores agradecem à CPRM - Serviço Geológico do Brasil, à Universidade Federal Rural do Rio de Janeiro e ao Programa de Pós-graduação em Recursos Minerais e Hidrogeologia do Instituto de Geociências da USP. RM agradece ao CNPq, pela concessão de uma Bolsa de Produtividade em Pesquisa (Proc. 300423/82-9) e PDJ agradece a CAPES pela bolsa de doutorado. Os autores agradecem ainda a Edison José Milani pelos comentários construtivos feitos ao manuscrito.

\section{Referências}

Almeida, F.F.M. 1980. Síntese sobre a tectônica da Bacia do Paraná. In: SIMPÓSIO REGIONAL DE GEOLOGIA, 3, Curitiba, 1980. Anais...Curitiba, SBG, p.1-20

Almeida, F.F.M. 1983. Relações tectônicas das rochas alcalinas mesozoicas da região meridional da Plataforma Sul-Americana. Revista Brasileira de Geociências, 13(3):139158.

Almeida, R.P. 2005. Tectônica e sedimentação do Ediacarano ao Ordoviciano: exemplos do Supergrupo Camaquã (RS) e do Grupo Caacupé (Paraguai Oriental). São Paulo, 224p. Tese de Doutorado, Programa de Pós-Graduação em Geoquímica e Geotectônica, Instituto de Geociências, Universidade de São Paulo.

Almeida, R.P., Janikian, L., Fragoso-Cesar, A.R.S. \& Fambrini, G. L. 2010. The Ediacaran to Cambrian Rift System of Southeastern South America: Tectonic Implications. Journal of Geology, 118: 145-161.

Angelier, J. \& Mechler, P. 1977. Sur une méthode graphique de recherché dês constraints principales également utilizable en tectonique et en séismologie: la méthode dês dièdres droits. Bulletin de la Société Géologique de France, 7:1309-1318.

Crepani, E. \& Medeiros, J.S. 1994. Imagens fotográficas derivadas de MNT do Projeto SRTM para fotointerpretação na Geologia, Geomorfologia e Pedologia. São José dos Campos: INPE.

Farr, T.G., Rosen, P. A., Caro E., Crippen, R., Duren, R., Hensley, S., Kobrick, M., Paller, M., Rodriguez, E., Roth, L., Seal, D., Shaffer, S., Shimada, J., Umland, J., Werner, M., Oskin, M., Burbank, D. \& Alsdorf, D. 2007. The Shuttle Radar Topography Mission. Reviews of Geophysics, 45: 33p.

Ferreira, A.C. \& Almeida, T.I.R. 1989. Tectônica transcorrente e imagens TM-Landsat aplicadas à prospecção de fluorita e barita em Santa Catarina. Revista Brasileira de Geociências, 19(1):207-223

Ferreira, F.J.F. 1982. Integração de dados aeromagnéticos e geológicos: configuração e evolução tectônica do Arco de Ponta Grossa. São Paulo, 170p. Dissertação de Mestrado, Instituto de Geociências, Universidade de São Paulo, São Paulo.

Freitas, R.C. 2005. Análise estrutural multitemática do sistema petrolífero Irati-Rio Bonito, Bacia do Paraná. Curitiba, 98p. Dissertação de Mestrado, Instituto de Geociências, Universidade Federal do Paraná,

Freitas, R.C. \& Rostirolla, S.P. 2005. Análise comparativa entre estruturas do embasamento e resposta em superfície na Bacia do Paraná, região entre os Estados do Paraná e Santa Catarina. In: SIMPÓSIO NACIONAL DE ESTUDOS TECTÔNICOS,10; INTERNATIONAL SYMPOSIUM ON TECTONICS, 4, Curitiba, Boletim de Resumos Expandidos, v.1, p. 41-44.

Freitas, M.A., Caye B.R., \& Machado J.L.F. 2002. Diagnóstico dos recursos hídricos subterrâneos do oeste do Estado de Santa Catarina - Projeto Oeste de Santa Catarina. Porto Alegre. CPRM/SDM-SC/SDA-SC/EPAGRI. 100p.

Fúlfaro, V.J, Saad, A.R., Santos, M.V. \& Vianna, R.B. 1982. Compartimentação e evolução tectônica da Bacia do Paraná. Revista Brasileira de Geociências, 12(4):590-611.

IPT. Instituto de Pesquisas Tecnológicas. 1982. Análise, interpretação e integração de lineamentos a partir de imagens (Radar-Landsat) e suas relações com a tectônica da Bacia do Paraná. São Paulo, IPT, Paulipetro, Consórcio CESP/ IPT, 356 p. (Relatório RT-342/82).

Jacques, P.D., Machado, R. \& Nummer, A.R. 2010. Lineamentos estruturais na borda leste da Bacia do Paraná em Santa Catarina: análise multiescala com base em imagens LANDSAT e SRTM. Pesquisas em Geociências, 37 (2): 117-131.

Jacques, P.D., Machado, R., Oliveira, R.G., Ferreira, F.J.F., Castro, L.G. \& Nummer, A.R. 2014. Correlation of lineaments (magnetic and topographic) and Phanerozoic brittle structures with Precambrian shear zones from the basement of the Paraná Basin, Santa Catarina State, Brazil. Brazilian Journal of Geology, 44(1):39-54.

Machado, R. \& Teixeira, W. 2008. Idades $\left({ }^{40} \mathrm{Ar} /{ }^{39} \mathrm{Ar}\right)$ do Magmatismo Alcalino do Distrito Alcalino de Lages, SC. In: SIMPÓSIO DE VULCALNISMO E AMBIENTES ASSOCIADOS, 4, 2008, Foz do Iguaçu. Boletim de Resumos, Foz do Iguaçu, SBG, 1 CD-ROOM.

Machado, R., Roldan, L.F., Jacques, P.D., Fassbinder, E. \& Nummer, A.R., 2012. Tectônica transcorrente Mesozoica-Cenozoica no Domo de Lages - Santa Catarina. Revista Brasileira de Geociências, 42(4):799-811.

Milani, E.J. \& Ramos, V.A. 1998. Orogenias Paleozoicas no domínio sul-ocidental do Gondwana e os ciclos de subsidência da Bacia do Paraná. Revista Brasileira de Geociências, 28(4):473-484.

Milani, E.J., Melo, J.H.G., Souza, P.A., Fernandes, L.A. \& França, A.B. 2007. Bacia do Paraná. Boletim de Geociências da Petrobras 15(2):265-287.

Northfleet, A.A., Medeiros, R.A. \& Mülmann, H. 1969. Reavaliação dos dados geológicos da Bacia do Paraná. Boletim Técnico da Petrobras 12(3):291-346.

Paiva Filho, A., Crósta, A.P. \& Amaral, G.E. 1982. Utilização de dados de sensoriamento remoto no estudo estratigráfico e estrutural da Formação Serra Geral (Sul do Brasil). In: SIMPÓSIO BRASILEIRO DE SENSORIAMENTO REMOTO, 2, 1982, Brasília, Atas... Brasília, SBG, p.135-141. 
Picada, R.S. 1968. Os sistemas de falhas da parte central do escudo Sul-Rio-grandense. In: CONGRESSO BRASILEIRO DE GEOLOGIA, 22, 1968, Belo Horizonte, Anais... Belo Horizonte, SBG, v.1, p.247-253.

Picada, R.S. 1971. Ensaio sobre a tectônica do Escudo Sul-rio-grandense: caracterização dos sistemas de falhas. In: CONGRESSO BRASILEIRO DE GEOLOGIA, 25, 1971, São Paulo, Anais... São Paulo, SBG, p. 167-191.

Reginato, P.A.R. \& Strieder, A.J. 2006. Caracterização estrutural dos aqüíferos fraturados da Formação Serra Geral na região nordeste do Estado do Rio Grande do Sul. Revista Brasileira de Geociências, 36(1):13-22.

Reiter, F. \& Acs, P. 1995. Tectonics FP - A computer program for structural geology. Disponível em < http://www.tectonicsfp.com> Acessado em: 30 jan. 2012.

Ribeiro, M. 1970. Geologia da Folha de Bom Jardim, RGS. Boletim do Departamento Nacional da Produção Mineral, Divisão de Geologia e Mineralogia, 247:1-141.

Ribeiro, M. 1980. Geossuturas do Escudo do Rio Grande do Sul. In: CONGRESSO BRASILEIRO DE GEOLOGIA, 31, 1980, Camboriú, Anais... Camboriú, SBG, v. 5, p. 27092178.

Riccomini, C. 1989. O Rift Continental do Sudeste do Brasil. São Paulo, 256p. Tese de Doutoramento, Instituto de Geociências, Universidade de São Paulo.

Riccomini, C. 1995. Tectonismo gerador e deformador dos depósitos sedimentares pós-gondvânicos da porção centro-oriental do Estado de São Paulo e áreas vizinhas. São Paulo, 100 p. Tese de Livre-docência, Instituto de Geociências, Universidade de São Paulo.

Riccomini, C., Velázquez, V.F. \& Gomes, C.B. 2005. Tectonic controls of the Mesozoic and Cenozoic alkaline magmatism in central-southeastern Brazilian Platform. In: Gomes C.B. \& Comin-Chiaramonti P. (Eds.) Mesozoic to Cenozoic alkaline magmatism in the Brazilian Platform. São Paulo: EDUSP-FAPESP, 2005, p. 31-55.

Roldan, L.F. 2007. Tectônica rúptil Meso-Cenozóica na Região do Domo de Lages, SC. São Paulo, 106p. Dissertação de Mestrado, Programa de Pós-Graduação em Geoquímica e Geotectônica, Universidade de São Paulo.
Roldan, L.F., Machado, R., Steiner, S.S. \& Warren, L.V. 2010. Análise de Lineamentos Estruturais no Domo de Lages (SC) Com Uso de Imagens de Satélite e Mapas de Relevo Sombreado. Geologia USP, 10(2):57-72.

Scheibe, L.F., Kawashita, K. \& Gomes, C.B., 1985. Contribuição à geocronologia do Complexo Alcalino de Lages, SC. In: SIMPÓSIO SUL-BRASILEIRO DE GEOLOGIA, 2, 1985, Florianópolis, Atas... Florianópolis, SBG, p. 299-307.

Soares, A.P., Soares, P.C., Bettú, D.F. \& Holz, M. 2007. Compartimentação estrutural da Bacia do Paraná: a questão dos lineamentos e sua influência na distribuição do Sistema Aquífero Guarani. Geociências UNESP, 26(4):297-311.

Strugale, M. 2002. Arcabouço e evolução estrutural do Arco de Ponta Grossa no Grupo São Bento (Mesozóico): implicações na hidrodinâmica do Sistema Aqüífero Guarani e na migração de hidrocarbonetos na Bacia do Paraná. Curitiba, 154p. Dissertação de Mestrado, Instituto de Geociências, Universidade Federal do Paraná.

Strugale, M., Rostirolla, S.P., Mancini, F., Portela Filho, C.V., Ferreira F.J.F. \& Freitas, R.C. 2007. Structural framework and Mesozoic-Cenozoic evolution of Ponta Grossa Arch, Paraná Basin, southern Brazil. Journal of South American Earth Sciences, 24:203-227.

Wildner, W. 2004. Estratigrafia do magmatismo Serra Geral na Bacia do Paraná - Conceitos básicos e divisão faciológica. In: REUNIÃO ABERTA DA COMISSÃO BRASILEIRA DE ESTRATIGRAFIA / SBG / Porto Alegre, 2004.

Zalán, P.V., Wolff, S. \& Conceição, J.C. de J. 1987. Tectônica e sedimentação da Bacia Sedimentar do Paraná. In: SIMPÓSIO SUL-BRASILEIRO DE GEOLOGIA, 3, 1987, Curitiba. Atas... Curitiba, SBG, v. 1, p. 441-474.

Zalán, P.V., Wolff S., Conceição J.C., Marques A., Astolfi M.A.M., Vieira I.S. \& Appi V.T. 1990. Bacia do Paraná. In: Origem e evolução de Bacias Sedimentares. Petrobrás, Rio de Janeiro, p. 135-164.

Zalán, P.V., Wolff S., Conceição, J.C.J., Astolfi, M.A.M., Vieira I.S., Appi, V.T. Zanotto, O.A. \& Marques, A. 1991. Tectonics and sedimentation of the Paraná Basin. In: GONDWANA SYMPOSIUM, 7: São Paulo, Brazil, Proceedings..., São Paulo, p. 83-117.

Manuscrito 501.

Editores: Edinei Koester e Paulo A. Souza. 